\title{
TEORIA MONETÁRIA MODERNA E OS ENTES SUBNACIONAIS: O QUE A TEORIA MONETÁRIA MODERNA TEM A DIZER SOBRE A SITUAÇÃO FISCAL DO RIO GRANDE DO SUL
}

\section{MODERN MONETARY THEORY AND THE BRAZILIAN STATES: WHAT THE MODERN MONETARY THEORY HAS TO SAY ABOUT THE RIO GRANDE DO SUL'S FISCAL CONJUNCTURE}

\author{
Rafael Caminha Pahim*
}

Resumo: O presente artigo busca fazer uma discussão sobre a interpretação que a Teoria Monetária Moderna (TMM) pode alcançar sobre a conjuntura de deterioração fiscal dos entes federados brasileiros, cujo destaque é a situação do governo gaúcho, justamente por ser um caso emblemático no cenário nacional. O trabalho conta com uma síntese sobre o entendimento da Teoria Monetária Moderna quanto a funcionalidade do orçamento público, além de apresentar o cenário fiscal gaúcho dos últimos anos e uma breve discussão sobre a forma geral de financiamento dos estados brasileiros. Por fim, o artigo conclui que a TMM, dentro da negação pela austeridade fiscal prolongada e entendendo as atribuições institucionais brasileiras, contribui intelectualmente para uma agenda nacional de socorro aos estados por meio do orçamento público da união.

Palavras-chave: Teoria Monetária Moderna; Dívida Pública; Finanças Públicas.

Mestrando em Desenvolvimento Econômico no Programa de Pós-Graduação em Economia da Universidade Federal do Rio Grande do Sul E Pesquisador do Conselho Nacional de Desenvolvimento Científico e Tecnológico (CNPQ). Porto Alegre, Brasil. 


\begin{abstract}
This article seeks to discuss the interpretation which the Modern Monetary Theory (MMT) can bring on the Brazilian states' fiscal deterioration conjuncture, whose highlight is the situation of RS government, precisely because it is an emblematic case in the national scenario. The work includes a synthesis of the understanding of Modern Monetary Theory regarding the functionality of the public budget, in addition to presenting the RS state's fiscal scenario in recent years and a brief discussion on the general form of financing for Brazilian states. Finally, the article concludes that the MMT, within the denial of prolonged fiscal austerity and understanding the Brazilian institutional structure, intellectually contributes to a national aid agenda for the states through the union's public budget.
\end{abstract}

Keywords: Modern Monetary Theory; Public Debt; Public Finance.

Resumen: Este paper busca discutir la interpretación que la Teoría Monetaria Moderna (TMM) puede lograr sobre la situación de deterioro fiscal de las entidades federativas brasileñas, cuyo destaque es la situación del gobierno estatal, precisamente por tratarse de un caso emblemático en el escenario nacional. El trabajo incluye una sintesis del entendimiento de la Teoría Monetaria Moderna sobre la funcionalidad del presupuesto público, además de presentar el escenario fiscal del estado en los últimos años y una breve discusión sobre la forma general de financiamiento de los estados brasileños. Finalmente, el artículo concluye que el TMM, dentro de la negación de la austeridad fiscal prolongada y la comprensión de las atribuciones institucionales brasileñas, contribuye intelectualmente a una agenda nacional de ayuda a los estados a través del presupuesto público del únion.

Palabras clave: Teoría Monetaria Moderna; Deuda Pública; Finanzas públicas.

\title{
Introdução
}

Mesmo antes da crise econômica decorrente da pandemia de COVID-19, com seu profundo impacto negativo no produto interno bruto 
do país e das suas respectivas unidades federativas ${ }^{1}$ - consequentemente na arrecadação tributária-, o estado do Rio Grande do Sul (RS) já presenciava em uma profunda crise fiscal, cuja repercussão mais aparente à sociedade era o parcelamento salarial dos mais de 140 mil trabalhadores com vinculados ativos e dos mais de 150 mil aposentados e pensionistas do poder executivo gaúcho, processo que teve início em meados de 2015 (LARA, 2016; IPEA, 2020; SEFAZ, 2021). Neste cenário de insuficiência financeira vivida pelo governo estadual gaúcho, não apenas as obrigações de pessoal ficam comprometidas, mas o pagamento das demais despesas correntes e o próprio poder de investimento estadual (oriundo de recursos próprios) acabam sofrendo restrições monetárias.

Além da queda no bem-estar dos indivíduos que possuem seus rendimentos parcelados, a deterioração fiscal estadual tem impacto negativo no desenvolvimento economico do Rio Grande do Sul, justamente por diminuir a qualidade do ensino público, promover um aumento da criminalidade, gerar menor capacidade de investimento em infraestrutura e promover uma queda na eficiência dos serviços de saúde pública (menor oferta de materiais hospitalares, queda no número de funcionários e deterioração da infraestrutura das unidades de saúde) (TIMMERS, 2014; FOCHEZATTO et al, 2018; PETRY, 2019). Em virtude do pacto federativo adotado pela nação brasileira em 1988, os estados e munícipios possuem grandes implicações na prestação de serviços públicos à população (BOZZETO, 2017), de tal sorte que, qualquer conjuntura onde haja dificuldade no financiamento dos entes subnacionais, o seu efeito social é amplo e profundo. Assim sendo, analises sobre a conjuntura e o processo de desenvolvimento econômico e bem-estar populacional no Brasil devem, em alguma medida, passar pelo aprofundamento na situação fiscal dos entes subnacionais brasileiros.

Como destacado por Lara (2018), ainda que o Rio Grande do Sul seja um caso emblemático, o quadro das finanças públicas estaduais é, em geral, um problema crônico em todo o território nacional. Portanto, além das particularidades da trajetória fiscal de cada ente federativo, é preciso um olhar mais amplo para a problemática, onde a estrutura

${ }^{1}$ O PIB gaúcho em 2020 teve uma queda de 7\% em relação ao mesmo período do ano passado (pré-pandemia). Acima da queda registrada no país, a agropecuária teve grande impacto na queda, tanto pela crise da covid, como pela forte estiagem que atingiu o estado (DEE, 2021). 
institucional e orçamento público do governo central são peças chaves na determinação da conjuntura atual e passada dos resultados fiscais dos estados.

No que diz respeito à funcionalidade das finanças públicas nacionais, a literatura econômica se encontra em um momento particularmente especial, justamente pela quebra de paradigmas macroeconômicos seculares dentro do debate público e acadêmico, em especial no mainstream, processo que vem ganhando força, sobretudo, após a crise de 2008 e a estagnação global que a seguiu - incluindo o cenário brasileiro. A ideia ortodoxa do Sound Finance e a primazia pelo equilibrio fiscal dão lugar ao retorno da política fiscal como indutora do crescimento e desenvolvimento, ainda que o grau de utilização do instrumento fiscal não seja consenso nesta literatura crescente pós-2008 (ROMER, 2016; FAZZARI, 2017; RESENDE, 2017; 2019; STIRATI, 2020). A Teoria Monetária Moderna, uma vertente pós-keynesiana do pensamento econômico, vem tomando lugar de destaque no debate público e acadêmico como uma forma de pensar promissora na busca pelo protagonismo da agenda política contemporânea, fato ilustrado tanto pela atenção que lhe é dada por grandes nomes da academia (críticos ou não), quanto pelo uso da teoria como justificativa para uma série de projetos políticos que visam enfrentar as problemáticas sociais e ambiental do momento histórico atual ao redor do mundo ${ }^{2}$, inclusive no Brasil por meio das agendas propostas por autores da Unicamp, da UFRJ e do ex-diretor do Banco Central brasileiro André Lara Resende (WRAY et al, 2016; RESENDE, 2019; UNCTAD, 2019; KELTON, 2020).

Como destrinchado em Wray et al (2016) e Kelton (2020), a Teoria Monetária Moderna defende como uma das suas premissas fundamentais as Finanças Funcionais, cujo arcabouço intelectual, em síntese, compreende a política fiscal - mais especificamente o déficit público - como fator determinante na garantia do pleno emprego e do crescimento econômico, ao passo que o débito do setor público é, por defini-

${ }_{2}$ O programa politico da ala mais à esquerda do partido democrata é um case simbólico, ao passo que pregam o perdão das dívidas estudantis, uma reforma tributária altamente progressista e a estruturação de uma ampla política pública para reformar a matriz energética e produtiva norte americana, o Green New Deal (FRIEDMAN, 2019; KELTON, 2020). 
ção, um ativo do setor privado ${ }^{3}$, sendo o nivel de preços a restrição ao aprofundamento do déficit, visto que o país emissor da moeda nacional tem plena capacidade institucional de emitir a unidade de conta a fim de efetuar as trocas que entende necessário. Ainda dentro desta proposição, a teoria vai compartilhar a convicção da taxa de juros básica exógena. Além das Finanças Funcionais, a Teoria Monetária Moderna se faz valer de toda a estrutura pós-keynesiana, sobretudo aquela oriunda das obras de Hyman Minsky (WRAY et al, 2016; RESENDE, 2019).

Vergnhanini e Conti (2017) destacam a existência de um debate sobre o uso das premissas teóricas da Teoria Monetária Moderna em países periféricos, ou seja, aqueles que não possuem a capacidade de emitir uma moeda com status de reserva de valor internacional. Por sua vez, a proposta deste trabalho é jogar luz na forma que Teoria Monetária Moderna interpreta a situação fiscal das unidades federativas brasileiras, dadas as características institucionais que esses entes se valem dentro da estrutura política adotada no Brasil.

O presente artigo vai ser dividido em duas seções, além da introdução e das considerações finais: (1) Os preceitos básicos da Teoria Monetária Moderna sobre política fiscal e orçamento público; (2) A forma geral de financiamento das unidades federativas brasileiras e a conjuntura presente no orçamento estatal gaúcho. A conclusão busca sintetizar o que foi apresentado com o propósito de responder a proposta do trabalho.

\section{Teoria Monetária Moderna e o Orçamento Público}

Para compreender de forma sintética a visão da Teoria Monetária Moderna sobre a funcionalidade do orçamento público, a interpretação da teoria sobre a natureza da moeda ${ }^{4}$ é fundamental. Conforme as obras seminais Wray et al (2016) e Wray (2003), a vertente teórica em questão

3 Essa afirmação pressupõe uma economia fechada. Em um modelo de economia aberta, um débito do setor público pode ser ativo do setor privado ou setor externo. A lógica inversa é verdadeira.

4 Moeda neste trabalho é entendida no mesmo sentido de Money, diferente de currency. Algumas obras costumam fazer essa diferença adotando "dinheiro" como sinônimo de Money e moeda para currency. Não é o caso aqui. 
compreende a moeda a partir da sua função como unidade de conta das trocas de uma economia, sendo a origem desta unidade fruto da autoridade central da sociedade - os Estados, utilizando o termo mais moderno -, que a determina por meio da imposição de tributos. Essa orientação intelectual é chamada de Cartalismo, cujo papel dentro da Teoria Monetária Moderna é aprofundado com os estudos da antropologia econômica, mais especificamente nos trabalhos do David Graeber. Goodhart (1998) destaca que, ainda que a moeda tenha um papel importante na redução dos custos de transação de uma economia ${ }^{5}$, ela surge como uma forma de controle e organização da burocracia central, sendo essa unidade de conta manifestada das mais diversas formas, de tal sorte que toda e qualquer moeda é, naturalmente, uma construção social, ou seja, é fiduciária.

Vale destacar que, enquanto uma corrente pós-keynesiana, a Teoria Monetária Moderna compreende o modo de produção capitalista enquanto uma economia monetária da produção, ou seja, a moeda importa na decisão de gastos dos atores econômicos, justamente por ser um ativo que serve como reserva à incerteza fundamental. O princípio da demanda efetiva é conceito fundamental dentro do escopo analítico da teoria (LAVOIE, 2014; WRAY, 2016).

Ao passo que o Estado impõe o uso de uma determinada moeda (a fim de controlar e concretizar trocas no seu respectivo território), esse movimento desagua na criação de um ativo para quem vem a deter aquela unidade de conta, de tal sorte que esse ativo de outrem é um passivo estatal. Desta forma, toda moeda é um passivo do Estado e um ativo do detentor, sendo a liquidação dos tributos uma forma de destruição do passivo estatal - e dos ativos de outrem. Ainda que contraintuitivo, esse fato pode ser constatado no próprio balanço de ativos da autoridade monetária de um país com moeda soberana ${ }^{6}$, onde as reservas monetárias são entendidas como passivos do Banco Central. Nesse mesmo sentido, e em acordo com a teoria pós-keynesiana como um todo, o governo soberano central, por meio da autoridade monetária, tem controle autônomo sobre a sua taxa de juros básica, seja essa taxa estipulada por meio do mercado interbancário ou da remuneração dos compulsórios, visto

5 Visão adotada pela ortodoxia

6 País com moeda soberana, ou soberania monetária, é aquele que emite a moeda utilizada em território nacional de forma monopolística. 
que a taxa de juros básica é o preço pago pela posse de um passivo do estado em forma não-monetária (WRAY, 2016; CARVALHO et al, 2017; SERRANO, PIMENTEL, 2017; RESENDE, 2019).

À medida que a moeda é entendida como um passivo estatal cuja sua forma de ativo é usada pelos agentes frente a natureza incerta do mundo -, a Teoria Monetária Moderna, em conjunto com uma análise institucional, elenca uma das suas principais proposições teóricas: Países cujo Estado seja monetariamente soberano não encontram restrições financeiras para quitar seus compromissos em moeda nacional, a não ser por limites autoimpostos - cuja função tem caráter economico e político. Desta feita, as restrições que existem ao uso do orçamento público, além das limitações autoimpostas, são de caráter produtivo, isto é, a capacidade que a economia tem de responder à demanda do Estado, cuja resposta, frente o pleno uso da capacidade produtiva dos setores, é um processo inflacionário ${ }^{7}$ (WRAY, 2016; SERRANO, PIMENTEL, 2017; RESENDE, 2019; KELTON, 2020). Vergnhanini e Conti (2017) ainda aponta para as restrições de países com economias periféricas, cuja a moeda tem pouca capacidade de servir como reserva de valor internacional, onde mesmo com Estados soberanos em moeda nacional, o setor externo impõe limites a atuação do orçamento público, dado o impacto na taxa de câmbio e nas restrições junto às divisas externas em posse do país.

Serrano e Pimentel (2017) e Resende (2019) elucidam a afirmativa sobre o caráter ilimitado da fonte de financiamento do orçamento público soberano através de uma análise mais pormenorizada da institucionalidade brasileira e seu paralelo geral no mundo, ou seja, a natureza institucional da criação e destruição de moeda (incluindo seus direcionamentos). Em síntese, é por meio da relação entre o Banco Central e o Tesouro Nacional ${ }^{8}$ que a plena capacidade financeira aparece, justamente pelo Banco Central - instituição de Estado que responde aos desejos do grupo de poder via burocracia decisória ${ }^{9}$ - ser o órgão que

\footnotetext{
7 Enquanto vertente pós-keynesiana, a Teoria Monetária Moderna nega a Teoria Quantitativa da Moeda e suas variações, como o Novo Consenso Macroeconômico (LAVOIE, 2014; VERGNHANINI, CONTI, 2017; RESENDE, 2019). A bem da verdade, o processo inflacionário não impede um financiamento continuo do Estado, apenas o torna ineficiente e disruptivo.

8 No caso brasileiro, mais especificamente com a Conta Única do Tesouro.

9 No caso brasileiro, mais especificamente o congresso nacional.
} 
credita as unidades de conta na economia, sem que isso seja vinculado a nenhuma grandeza física, sendo, desta feita, um emissor de última instância. Ao que diz respeito à sua relação com o Tesouro, o Banco Central tem plena capacidade de creditar recursos financeiros junto a conta do Tesouro no seu balanço, desde que respeitando as limitações autoimpostas pela burocracia ${ }^{10}$, justamente pela autoridade monetária não enfrentar restrição na sua capacidade de creditar/criar unidades de conta. Sendo assim, duas características do sistema monetário moderno de países soberanos podem ser destacadas: (1) A emissão de títulos públicos é um meio pelo qual o Estado manipula a liquidez da economia, ao passo que troca uma divida não-remunerada (moeda) por uma divida remunerada a determinada taxa de juros ${ }^{11}$; E (2) os recursos arrecadados por meio de tributos não financiam o governo central, mas, tal como a emissão de títulos públicos, trabalham no controle da liquidez da economia, ao passo que essa função dos tributos são utilizados como instrumentos distributivo e de incentivos dentro da economia (WRAY, 2016; SERRANO, PIMENTEL, 2017; RESENDE, 2019; KELTON, 2020). Serrano e Pimentel (2017) ainda destacam a questão logística pelo qual os tributos não financiam os gastos do governo central, uma vez que o momento da tributação e dos gastos não coincidem. Os mesmos autores destrincham a exogeneidade da SELIC (taxa de juros básica da economia brasileira), ao passo que o Banco Central brasileiro tem plena capacidade de ofertar reservas bancárias no mercado interbancário.

Como dito anteriormente ao longo do capítulo, todos esses elementos que induzem a existência de uma plena capacidade de financiamento dizem respeito aos governos centrais que emitem a moeda nacional ${ }^{12}$, ou seja, aqueles cujo Banco Central, dentro da institucionalidade do Estado, é o creditador em última instância da unidade de conta nacional - estipulada por meio da tributação. Por óbvio, esse não é caso das famílias e das firmas ${ }^{13}$, nem dos bancos privados (ainda que

10 Um exemplo brasileiro é o Teto dos Gastos e a Regra de Ouro.

11 No Brasil, o Tesouro Nacional é obrigado a emitir títulos públicos para valores gastos que excedam a arrecadação com tributos.

${ }^{12}$ As nações membros da União Europeia são um exemplo de países não soberanos em moeda nacional.

${ }^{13}$ Como destaca Wray (2016), qualquer agente e instituição pode criar sua IOU (I owe you), ao passo que só é plenamente aceitada a IOU do Estado, visto que este impõe o pagamento de tributos com o uso da sua própria IOU. A capacidade que cada Estado tem em impor o pagamento de tributos é um aspecto que diz respeito sua condição histórica, institucional e militar. 
estes tenham a capacidade de emitir depósitos à vista ${ }^{14}$ ) e, dentro da estrutura institucional do federalismo brasileiro, dos entes federados e dos municipios (DE REZENDE, 2009; WRAY, 2016; SERRANO, PIMENTEL, 2017; RESENDE, 2019).

Em uma conjuntura de profunda crise fiscal dos entes federados brasileiros, onde o Rio Grande do Sul é um caso emblemático, um olhar mais cuidadoso é necessário para a forma de financiamento desses atores, a fim de determinar, justamente, se existe algum espaço para políticas de recuperação fiscal não austeras.

\section{O Financiamento Estadual e a Conjuntura Gaúcha}

A estrutura de financiamento dos 27 entes federados brasileiros possui, entre cada um deles, uma certa especificidade, seja nas alíquotas e na participação de determinados tributos, na fonte de financiamento para os déficits públicos e investimentos e no peso das transferências de recursos federais para os cofres estaduais. De todo modo, nenhum ente subnacional consegue se financiar inteiramente com recursos próprios, ou seja, os tributos de ordem estadual não arrecadam valores suficientes para cobrir os gastos cuja competência é do próprio ente federado administrar, uma vez que todo ente federado recebe do governo federal transferências de recursos, sobretudo nas áreas de saúde e segurança pública. A bem da verdade, está assimetria, por si só, não é fruto de um problema fiscal, justamente pelo pacto federativo brasileiro dividir a competência da administração pública entre suas 3 esferas, o que implica, justamente, na existência destas transferências de recursos para diversos fins entre os diferentes níveis da administração pública, sem que isso, obrigatoriamente, seja resultado da necessidade de financiamento para cobrir resultados fiscais deficitários (BOZZETO, 2017; LARA, 2018; PETRY, BRAATZ, MARTINEZ, 2018; BRAATZ, ROCHA, 2021).

\footnotetext{
${ }^{14}$ Depósitos à vista, ainda que sejam usados na quase totalidade das trocas, não possuem o status de reservas bancárias, que é a unidade de conta utilizada nas transações do Banco Central com os demais bancos e com o Tesouro Nacional, além de ser a unidade de conta que os bancos transacionam entre si no mercado interbancário (DE REZENDE, 2009; SERRANO, PIMENTAL, 2017). Vale lembrar que esse conceito trabalha sobre a ótica da endogeneidade monetária.
} 
Ainda sobre a estrutura institucional do pacto federativo brasileiro, um ponto extremamente relevante é, justamente, a noção que, além do governo central, nenhum outro ente subnacional tem o instrumento da relação direta com a emissão de reservas do banco central, ou seja, com exceção da administração central, todo e qualquer ente subnacional demanda que haja recursos disponiveis em caixa antes de efetivar o seu gasto, sendo esses recursos oriundos de tributos, transferências entre entes ou empréstimos ${ }^{15}$. Desta forma, dessemelhante ao que experimenta o governo central, esses entes subnacionais possuem restrições financeiras exógenas (não autoimpostas) em moeda corrente (nacional), por consequência podendo haver uma dissincronia entre o fluxo de entrada (receita) e saída (gastos), como é caso do parcelamento de salários e aposentadorias por parte do governo gaúcho. A bem da verdade, os entes federados podem cobrir seus déficits e dissincronias com a obtenção de crédito junto a instituições financeiras e a própria União, porém, tal como ocorre em famílias e firmas, esses créditos incorrem em passivos cujo pagamento advém das rendas previamente adquiridas, de tal sorte que sem a disponibilidade de recursos das receitas primárias, o ente precisa recorrer a uma nova obtenção de crédito para cobrir os seus passivos, a fim de não incorrer em default. Usualmente, as unidades federativas recorrem a união para cobrir seus déficits (SERRANO, PIMENTEL, 2017; PETRY, BRAATZ, MARTINEZ, 2018; BRAATZ, ROCHA, 2021).

O uso da união como uma fonte de receita para cobrir os déficits é um aspecto importante, justamente pelo fato de a união não incidir em restrições financeiras em moeda nacional, ao passo que as condições de financiamento ${ }^{16}$ impostas pelo governo central aos seus entes federados é uma decisão que visa administrar a liquidez da economia (mais especificamente destes agentes), sem que isso garanta maior ou menor capacidade orçamentária para o poder central ${ }^{17}$.

\footnotetext{
${ }^{15}$ Ainda que não seja uma analogia correta, o caso dos entes subnacional, onde a necessidade de uma renda prévia ao gasto existe, se aproxima mais do discurso, usualmente ortodoxo, no qual se compara o orçamento familiar com o do estado. A analogia ainda se mantém falsa por uma série de questões que não vão ser adentradas, mas é mais coerente com a realidade do que a mesma analogia quando é usada para o governo central - ver Kelton (2020) e Serrano e Pimentel (2017) para críticas e uso da analogia no debate público.

16 Prazos, taxas, formas de parcelamento e etc.

${ }^{17}$ Essa afirmação é dada em termos amplos. Se existe uma limitação autoimposta cuja receita dos passivos estaduais impacta positivamente no orçamento federal, então há uma maior capacidade, dada a limitação autoimposta.
} 
Dentro da conjuntura nacional de crise fiscal dos governos estaduais, o Rio Grande do Sul é um caso emblemático, seja pela profundidade da crise, quanto pela trajetória que o Tesouro Estadual incorreu ao longo das últimas décadas, onde a Lei Kandir (formulada em 1996) e a Lei de Responsabilidade Fiscal (implementada em 2001) são entendidas como instituições fundamentais para compreender esta trajetória que culmina na crise atual (BOZZETTO, 2017; LARA, 2018; PETRY, BRAATZ, MARTINEZ, 2018).

De forma sintética, a estrutura fiscal do Rio Grande do Sul é, historicamente, deficitária, situação que vem se agravando com desde 2008 e a estagnação econômica brasileira no período pós-2014, sem contar a continuidade do crescimento das despesas correntes estaduais. No que diz respeito a estagnação econômica nacional, o PIB gaúcho é fortemente correlacionado com a atividade econômica do país, de tal forma que, sendo a arrecadação gaúcha pró-cíclica, o período de 2008 e pós-2014 comprometeram a trajetória de crescimento real da arrecadação rio-grandense. Ao que pesa o continuo crescimento das despesas correntes estaduais, o orçamento gaúcho além de apresentar uma forte rigidez, fazendo com que todo e qualquer ajuste para equalizar os fluxos fiscais sejam dados no médio e longo prazo - o que exige comprometimentos políticos para além de apenas $4 \operatorname{anos}^{18}$-, possui grande parte dos recursos destinados para pagamento de pessoal, justamente uma rubrica que, por força de diversas leis, acaba sendo (em parte) reajustada anualmente. Leis de mínimo para educação e saúde completam a rigidez das despesas e a menor capacidade de reversão no curto prazo de uma trajetória crescente dos gastos (LARA, 2018; LARA, 2018; PETRY, BRAATZ, MARTINEZ, 2018; BRAATZ, ROCHA, 2021). Os seguintes gráficos, retirados, respectivamente, de Petry, Braatz e Martinez (2018) e Lara (2018) destacam a trajetória fiscal e a correlação do PIB nacional e gaúcho:

$\overline{18 \text { O Rio Grande }}$ do Sul nunca teve, desde a redemocratização, um governador reeleito. 
Gráfico 1 - Resultado primário em relação ao PIB gaúcho (em \%) de 1971 a 2017

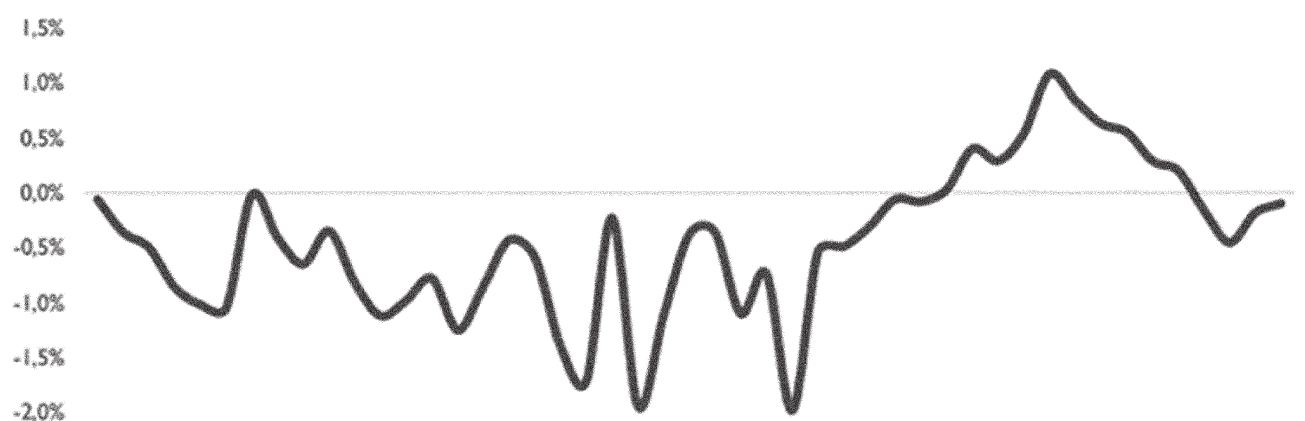

197119731975197719791981198319851987198919911993199519971999200120032005200720092011201320152017

Fonte: Petry, Braatz e Martines (2018). Dados retirados o SEFAZ RS e PLOA 2017.

Gráfico 2 - Taxas anuais de crescimento do PIB brasileiro e gaúcho (2003 - 2017)

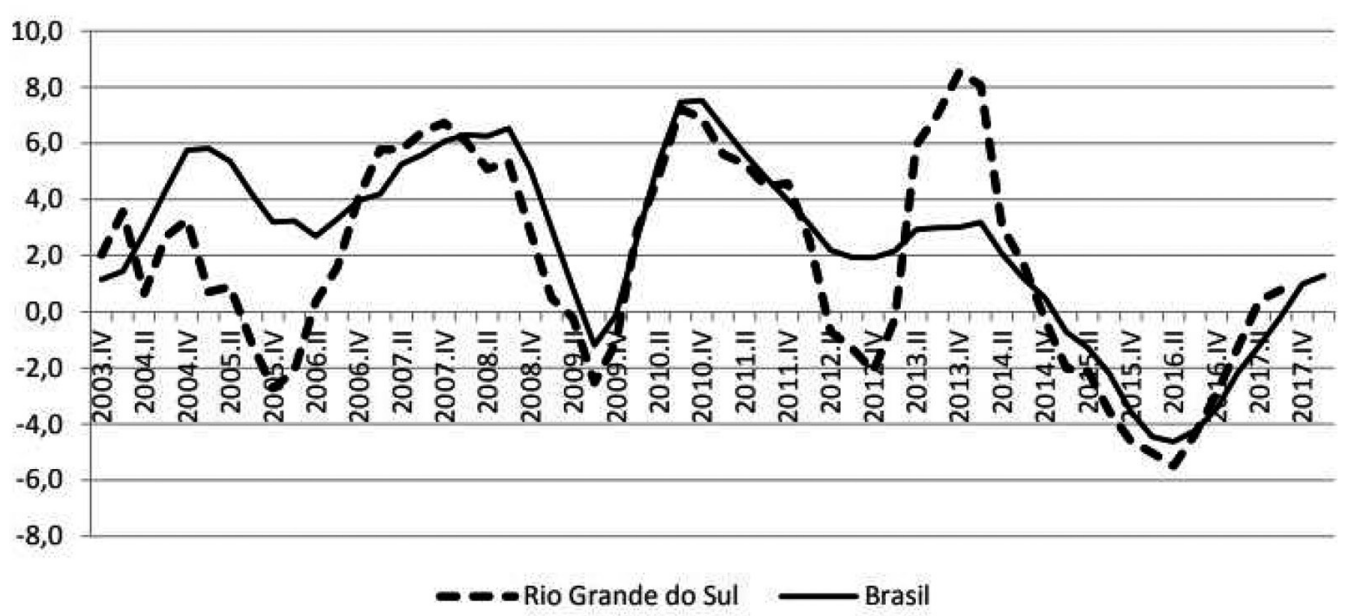

Fonte: Lara (2018). Dados retirados do IBGE e da FEE.

Ambos os dados trabalham com os cenários pré-pandemia, porém com a queda da atividade nacional e gaúcha durante a crise sanitária, sendo a queda na atividade rio-grandense mais acentuada em decorrência da estiagem (DEE, 2021), o cenário de desarranjo fiscal não apresentou nenhuma reversão de tendência, ainda que, segundo o TE/ RS (2021), o RS apresentou um déficit orçamentário de quase R\$ 800 milhões em 2020, ao passo que 2019 chegou a registrar uma rubrica deficitária de $\mathrm{R} \$ 3$ bilhões. 
Os dados referentes à série histórica apresentados no gráfico 1 destacam marcos importantes na estrutura fiscal dos entes federados: A Lei de Responsabilidade Fiscal (Lei Complementar 101/2000), cujo impacto foi positivo para o equilibrio fiscal nos anos que se seguiram, com um aumento expressivo do superavit até 2008 - tendo em vista o efeito da alta no preço das commodities após o biênio 2004-2005 -, regredindo (ainda que em estágio superavitário) até 2014, quando volta ao déficit crônico. Os demais estados seguem a mesma lógica experimentada pelo Rio Grande do Sul (PETRY, BRAATZ, MARTINEZ, 2018). Outros marcos históricos que compõem a caminhada fiscal das unidades federativas sendo o RS ainda um case significativo - é (1) a implementação do Plano Real, cujo resultado foi o fim do processo de hiperinflação brasileira e do uso do imposto inflacionário como parte das receitas estaduais, e (2) a instauração da Lei Kandir (Lei Complementar $n^{\circ} .87 / 96$ ), que acarretou em uma perda fiscal significativas para as receitas estaduais, visto que seu papel é promover a desoneração do pagamento do ICMS, das exportações de produtos industrializados, semielaborados, serviços e produtos primários (BOZZETO, 2017; PETRY, BRAATZ, MARTINEZ, 2018). O gráfico 3 apresenta a evolução da dívida pública gaúcha (em preços constantes) de 1998 até 2020:

Gráfico 3 - Evolução da Divida Pública do RS (1998-2020). Preços constantes (deflacionamento pelo IPCA-IBGE)

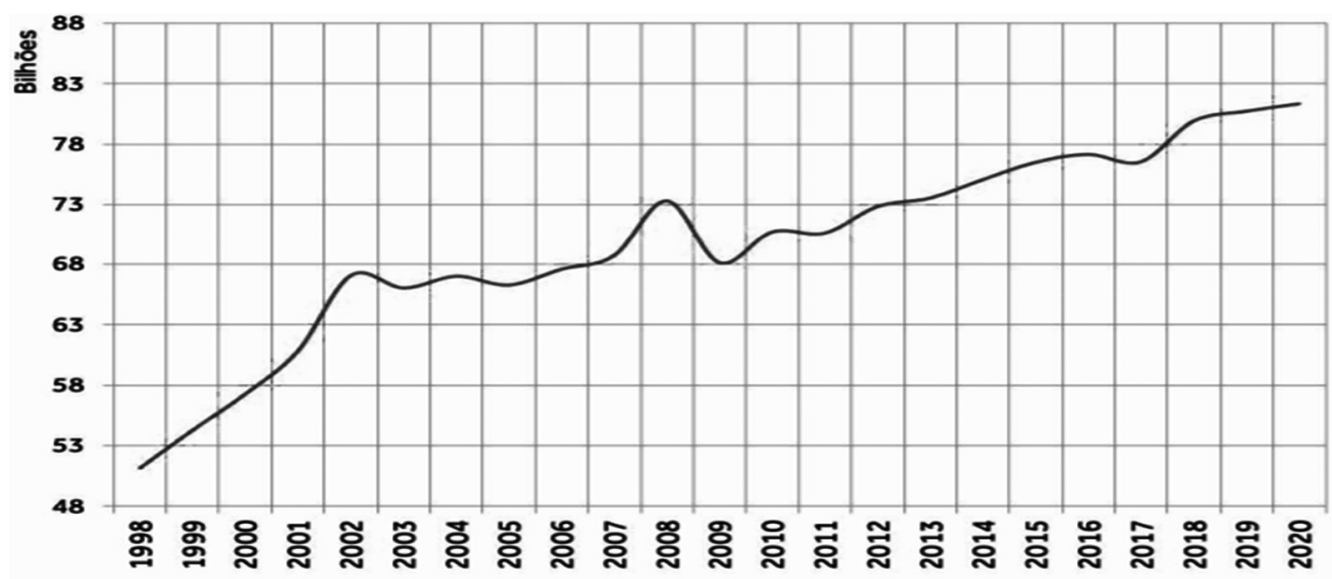

Fonte: TE/RS (2021). Esse dado não inclui precatórios judiciais e parcelamentos a autarquias e fundações. 
Ao final de 2020, dos $\mathrm{R} \$ 81,3$ bilhões da dívida pública gaúcha, $\mathrm{R} \$ 69,1$ bilhões são devidos à União. Quanto os precatórios judiciais e parcelamentos a autarquias são adicionadas ao passivo do Rio Grande do Sul, a Divida Consolidada Líquida do RS atinge a marca de $\mathrm{R} \$ \mathbf{9 3 , 3}$ bilhões, colocando o estado gaúcho na quarta posição de maiores devedores entre todas as unidades federativas ${ }^{19}(\mathrm{TE} / \mathrm{RS}, 2021)$.

No final das contas, dado o cenário profundo de deterioração fiscal dos entes federados, para que os governos estaduais consigam honrar suas obrigações constitucionais e agendas de desenvolvimento regionais, é imprescindível uma reestruturação da situação fiscal que a institucionalidade brasileira impõe aos seus entes subnacionais. Ainda que os governos locais consigam articular receitas extraordinárias esporádicas, como venda de ativos e de folhas de pagamento para ban$\cos ^{20}$, essas medidas costumam ter impacto no curtíssimo prazo e sem maiores efeitos no estoque e na trajetória dos passivos estaduais. Desta feita, a resolução para a conjuntura em questão passa, invariavelmente, por 3 trajetos, não excludentes entre si: (A) Um longo e profundo ajuste fiscal nas contas estaduais; (B) A presença de um alto e prolongado crescimento da economia nacional, dada a característica pró-cíclica das economias e receitas estaduais, junto com a rigidez dos gastos; e (C) uma agenda econômica nacional que garanta os fluxos monetários necessários para estabilizar a condição fiscal dos governos estaduais, processo que, a fim de garantir a salubridade fiscal, não pode impor um passivo financeiro como contrapartida.

\section{Considerações Finais}

Dentro do cenário de deterioração fiscal dos estados e, consequentemente, da queda na qualidade e disponibilização de serviços públicos essenciais, um olhar cuidadoso para uma resolução sustentada e que não afeta negativamente o desenvolvimento economico e social das regiões e do país como um todo - dada as responsabilidades cons-

${ }^{19}$ O Total das Dívidas Consolidadas Líquidas dos entes federados brasileiros atinge a marca de $\mathrm{R} \$ 840,87$ bilhões, segundo o Relatório Anual da Dívida Pública Estadual (2021), com dado dos relatórios de gestão das secretarias estaduais.

${ }^{20}$ Caso adotado pelo Estado do Rio Grande do Sul, quando este vendeu a folha de pagamento para o Banrisul (PETRY, BRAATZ, MARTINEZ, 2018). 
titucionais dos entes federados - é crucial. As opções que podem ser elencadas para equalizar os fluxos de entrada e saída de recursos, ainda que não de forma excludente entre si, são: (1) Ajuste fiscal profundo e prolongado; (2) Um crescimento economico de longo prazo e com taxas chinesas; E (3) uma agenda econômica nacional que garanta os fluxos monetários necessários para honrar os passivos e compromissos de desenvolvimento regional e social. Entre as escolhas possiveis, a única que depende inteiramente da administração estadual é a promoção de um ajuste fiscal amplo e prolongado, todavia, essa opção acarreta efeitos negativos, principalmente no médio e longo prazo, na prestação de serviço e na promoção de investimentos e renda - mesmo assim, sem garantias de seu pleno sucesso, dado a dependência das receitas estaduais junto à performance da atividade econômica nacional.

O crescimento economico prolongado e com taxas chinesas, e a imposição de uma agenda nacional para salvar os entes federal são políticas e resultados econômicos que os governos estaduais tem pouco ou nenhum apelo. Desta feita, há uma série de escolas do pensamento econômico que traduzem diversas medidas para garantir o requerido crescimento economico e uma agenda nacional de ajuda aos estados, inclusive com uso de políticas de austeridade, como a promovida pelo Tesouro Nacional na busca pela renegociação das dividas estaduais ${ }^{21}$.

A Teoria Monetária Moderna, enquanto vertente do pensamento economico ligada à escola pós-keynesiana, vai no sentido oposto de uma agenda econômica promotora de ajustes fiscais, defendendo uma atuação ativa do governo central na administração da demanda agregada e garantia de serviços públicos e direitos adequados à população. Nesse sentido, a Teoria Monetária Moderna argumenta que os Estados monetariamente soberanos têm uma disponibilidade ilimitada de recursos monetários em unidade de conta própria (passivo monetário), onde a oferta de bem e serviços dos setores responde aos estímulos governamentais até a eclosão de uma pressão inflacionário em decorrência do pleno uso dos fatores de produção, ao mesmo tempo que controlam, de forma autônoma, a taxa de juros básica da economia. As afirmativas da teoria em questão servem tanto para países cuja moeda é reserva in-

${ }^{21}$ Ver Lara (2018), Petry, Braatz e Martinez (2018) e TE/RS (2021) para mais detalhes quanto aos termos da renegociação. 
ternacional ${ }^{22}$, quanto países de moeda inferior na hierarquia monetária internacional, como o caso do Brasil, dado que, nessas economias de moeda fraca, o setor externo entra como uma variável capaz de restringir a atuação da autoridade central no arranjo da política econômica.

Portanto, em termos de entes subnacionais brasileiros, a Teoria Monetária Moderna, se valendo da estrutura institucional nacional, compreende os governos estaduais como agentes econômicos incapazes de emitir a unidade de conta que utilizam nas suas transações, de tal forma que dependem de um fluxo de renda oriundo de outro agente para que, então, possa efetivar seu gasto - o que, dentro da realidade institucional brasileira, pode acarretar em dessincronizações de receita e as ordens de despesa no dia a dia. Sendo assim, sabendo da conjuntura de crise fiscal dos estados brasileiros, a única encontrada pelas premissas da Teoria Monetária Moderna é uma articulação em âmbito nacional que garanta um fluxo de recursos para os entes federal, a fim de manter os compromissos junto à população, através, justamente, da capacidade que a união possui para se autofinanciar. Existe uma gama diversa de caminhos para essa articulação entre Tesouro Nacional e Tesouros Estaduais, seja tanto por meio de transferências diretas, quanto pelo perdão das dívidas bilionárias que já perduram a décadas, cujos encargos, além de pesarem no orçamento estadual, possuem um horizonte de duas a três décadas para serem pagos, assumindo que não haja outras renegociações ${ }^{23}$. Caso uma agenda nacional não seja adotada, o único caminho lógico para o equilíbrio das contas é a adoção de uma política fortemente austera juntos aos entes subnacional, todavia, o custo social dessa política é elevadíssimo, tendo em vista os compromissos estabelecidos pela Constituição Federal aos estados brasileiros ${ }^{24}$. Sendo a Teoria Monetária Moderna uma construção teórica pró-crescimento e pró-desenvolvimento economico e social, uma agenda de austeridade não cobre seu ideal teórico.

\footnotetext{
${ }^{22}$ Ex: Estados Unidos da América e o dólar.

${ }^{23}$ Lembrando que, como destaca a Teoria Monetária Moderna, os recursos que a união recolhe junto aos Tesouros Estaduais não financiam o governo central, apenas administram a liquidez da economia nas regiões;

${ }^{24}$ Segundo o TE/RS (2021), as despesas efetivas do governo gaúchos superaram a marca dos $R \$ 47$ bilhões. Assim sendo, uma política profunda de austeridade fiscal impacta, inclusive, na própria demanda agregada da região - e do país se grande parte dos entes seguirem o mesmo caminho - dado o tamanho do orçamento estadual.
} 


\section{Referências}

BOZZETO, Ângela. Lei Kandir. As finanças do Estado do Rio Grande do Sul e o pacto federativo. Trabalho de Conclusão de Curso da graduação de ciências econômicas - UFRGS, 2017.

BRAATZ, Jacó; DA ROCHA, Mariana Mariano. Deliberações em nível federal e impactos sobre as finanças públicas do Rio Grande do Sul. Revista de Economia, v. 42, n. 78, p. 480-505, 2021.

CARVALHO, Fernando et al. Economia monetária e financeira: teoria e politica. Elsevier Brasil, 2017

DE REZENDE, Felipe Carvalho. The nature of government finance in Brazil. International Journal of Political Economy, v. 38, n. 1, p. 81-104, 2009.

DEE. Nota Técnica $n^{\circ} 34$ do Departamento de Economia e Estatística. 2021

FAZZARI, Steven M.; CYNAMON, Barry Z Secular demand stagnation in the 21 st century US economy. In: Preliminary draft prepared for INET Secular Stagnation Conference. 2017.

FOCHEZATTO, Adelar; Petry, Guilherme; BRAATZ, Jacó; MARCONDES, Henrique Romão. Análise dos efeitos dos gastos públicos estaduais em educação sobre a criminalidade nos municipios do Rio Grande do Sul. Texto para discussão TE/RS n 07, 2018.

FRIEDMAN, Lisa. What is the Green New Deal: A climate proposal, Explained. New York Times, New York, 21 Feb. 2019. Disponivel em <https://www.nytimes.com/2019/02/21/climate/greennewdealquestionsanswers.html>. Acesso em: 23 set. 2021.

GOODHART, Charles AE. The two concepts of money: implications for the analysis of optimal currency areas. European Journal of Political Economy, v. 14, n. 3, p. 407-432, 1998.

IPEA. Atlas do Estado Brasileiro, 2020. Disponível em <https://www. ipea.gov.br/atlasestado/consulta/85>. Acesso em 20 set. 2021. 
KELTON, Stephanie. The deficit myth: Modern Monetary Theory and how to build a better economy. Hachette UK, 2020.

LARA, Fernando Maccari. Análise da conjuntura econômica brasileira em 2015-2018 e perspectivas para 2019-2022. Textos para discussão TE/RS n ${ }^{\circ} 15,2018$.

LARA, Gabriela. Parcelamento de salários vira rotina no governo do RS. Jornal Estadão, 2016. Disponível em <https://economia.estadao.com. $\mathrm{br} /$ noticias / geral, parcelamento-de-salarios-vira-rotina-no-governo-do-rs, $10000026081>$. Acesso em 21 set. 2021.

LAVOIE, Marc. Post-Keynesian economics: new foundations. Edward E1gar Publishing, 2014.

PETRY, Guilherme Corrêa. Avaliação dos efeitos do gasto público no desenvolvimento dos municipios gaúchos utilizando painéis dinâmicos. Dissertação de mestrado do Programa de Pós-Graduação em Economia do Desenvolvimento - PUCRS, 2019.

PETRY, Guilherme; BRAATZ, Jacó; MARTINEZ, Paolo. Perspectivas para as finanças públicas do RS no periodo de 2019 a 2025. Textos para discussão TE/RS n¹0, 2018.

RESENDE, André Lara. Consenso e contrassenso: Déficit, divida e previdência. Instituto de Estudos de Política Econômica/Casa das Garças (IEPE/CdG), Rio de Janeiro, v. 47, fev. 2019.

RESENDE, André Lara. Juros, moeda e ortodoxia: teorias monetárias e controvérsias políticas. Portfolio-Pinguim, 2017.

ROMER, Paul. The trouble with macroeconomics. The American economist, Pittsburg, v.20, p. 1-20, set. 2016.

SEFAZ. Quantitativo de Cargos Inativos e Pensões Vitalícias com relação a agosto de 2021, 2021. Disponivel em <https://tesouro.fazenda. rs.gov.br/lista/3759/despesa-de-pessoal>. Acesso em 20 set. 2021.

SERRANO, Franklin; PIMENTEL, Kaio. será que "acabou o dinheiro"? financiamento do gasto público e taxas de juros num país de moeda soberana. Revista de Economia Contemporânea, v. 21, 2017. 
STIRATI, Antonella; GIRARDI, Daniele; PATERNESI MELONI, Walter. Reverse hysteresis? Persistent effects of autonomous demand expansions. Cambridge Journal of Economics, v. 44, n. 4, p. 835-869, 2020.

TE/RS. Relatório Anual da Divida Pública Estadual (RS), $12^{\circ}$ edição, 2021.

TIMMERS, Diego. Importância do investimento público na formação do PIB do Rio Grande do Sul. Trabalho de Conclusão do Curso de extensão em finanças públicas - UFRGS, 2014.

UNITED NATIONS CONFERENCE ON TRADE AND DEVELOPMENTUNCTAD/ONU. Financing a global New Green Deal. New York: ONU, 2019.

VERGNHANINI, Rodrigo; DE CONTI, Bruno. Modern Monetary Theory: a criticism from the periphery. Brazilian keynesian review, v. 3, n. 2, p. 16-31, 2017.

WRAY, L. Randall. Trabalho e moeda hoje: A chave para o pleno emprego e a estabilidade dos preços. Rio de Janeiro: UFRJ/Contraponto, 2003.

WRAY, L. Randall; MITCHELL, William; WATTS, Martin. Modern Monetary Theory and practice: An introductory text. Seattle: Amazon Company, 2016. 
